\title{
DIGITALCOMMONS
}

@WAYNESTATE -

Wayne State University

Kinesiology, Health and Sport Studies

College of Education

$1-1-2008$

\section{Teachers' Perspectives on the Use of Pedometers as Instructional Technology in Physical Education: A Cautionary Tale}

\author{
Nate McCaughtry \\ Wayne State University, aj4391@wayne.edu \\ Kimberly L. Oliver \\ New Mexico State University \\ Suzanna Rocco Dillon \\ Wayne State University, ar8670@wayne.edu \\ Jeffrey J. Martin \\ Wayne State University, aa3975@wayne.edu
}

\section{Recommended Citation}

McCaughtry, N., Dillon, S. R., Martin, J. J., \& Oliver, K. L. (2008). Teachers' perspectives on the use of pedometers as instructional technology in physical education: A cautionary tale. Journal of Teaching in Physical Education, 27(1), 83-99.

Available at: http://digitalcommons.wayne.edu/coe_khs/24 


\title{
Teachers' Perspectives on the Use of Pedometers as Instructional Technology in Physical Education: A Cautionary Tale
}

\author{
Nate McCaughtry, ${ }^{1}$ Kimberly L. Oliver, ${ }^{2}$ Suzanna Rocco Dillon, ${ }^{1}$ \\ and Jeffrey J. Martin ${ }^{1}$
}

${ }^{1}$ Wayne State University and ${ }^{2}$ New Mexico State University

\begin{abstract}
We used cognitive developmental theory to examine teachers' perspectives on the use of pedometers in physical education. Twenty-six elementary physical education teachers participating in long-term professional development were observed and interviewed twice over 6 months as they learned to incorporate pedometers into their teaching. Data were analyzed via constant comparison. The teachers reported four significant shifts in their thinking and values regarding pedometers. First, at the beginning, the teachers predicted they would encounter few implementation challenges that they would not be able to overcome, but, after prolonged use, they voiced several limitations to implementing pedometers in physical education. Second, they anticipated that pedometers would motivate primarily higher skilled students, but found that lesser skilled students connected with them more. Third, they moved from thinking they could use pedometers to teach almost any content to explaining four areas of content that pedometers are best suited to assist in teaching. Last, they shifted from seeing pedometers as potential accountability tools for student learning and their teaching to identifying key limitations to using pedometers for assessment. Our discussion centers on connecting these findings to teacher learning and professional development, and on the implications for teacher educators and professional development specialists advocating pedometers in physical education.
\end{abstract}

Keywords: physical education, teaching, technology

During the last decade, many educators have begun advocating the use of pedometers in physical education as technological supplements to traditional teaching methods (e.g., Pangrazi, Beighle, \& Sidman, 2003). The research and advocacy concerning pedometers has evolved into a number of streams. For example, educational advocates and manufacturers have explained how pedometers function. They capture users' step counts, time in movement activity, and energy

McCaughtry, Dillon, and Martin are with the Department of Kinesiology, Health, and Sport Studies, Wayne State University, Detroit, MI, and Oliver is with PERD, New Mexico State University, Las Cruces, NM. 
expenditure (Cuddihy, Pangrazi, \& Tomson, 2005; Morgan, Pangrazi, \& Beighle, 2003; Pangrazi et al., 2003; President's Council on Physical Fitness and Sports, 2002).

Researchers have also examined whether pedometers yield accurate readings of those measures (Cardon \& De Bourdeaudhuij, 2004; Crouter, Schneider, Karabulut, \& Bassett Jr., 2003; Kilanowski, Consalvi, \& Epstein, 1999; Louie \& Chan, 2003; Rowe, Mahar, Raedeke, \& Lore, 2004; Schneider, Crouter, Lukajic, \& Bassett Jr., 2003; Scruggs et al., 2003; Scruggs, Beveridge, Watson, \& Clocksin, 2005; Tudor-Locke \& Myers, 2001; Tudor-Locke, Williams, Reis, \& Pluto, 2002). The foremost finding from this growing body of work is that in controlled and highly supervised environments pedometers can indeed accurately record the quantity of participants' physical activity.

The education-related literature has focused on helpful suggestions for K-12 teachers about how to incorporate pedometers into their teaching (Cuddihy et al., 2005; Morgan et al., 2003; Pangrazi et al., 2003; President's Council on Physical Fitness and Sports, 2002). Suggestions include effectively mounting pedometers, distributing and collecting them during class periods, maintaining them (e.g., changing batteries), introducing them to students, resetting them, and calculating distances traveled based on step counts and stride lengths.

Pedometer writers also explain the educational outcomes that might be possible in physical education classes. These include teaching students that all activity is beneficial, whether they are achieving recommended daily step counts, the need for physical activity, how many steps different types of physical activities yield, how to self-assess physical activity, to generally value physical activity, and motivating students to be active (Beighle, Pangrazi, \& Vincent, 2001; Cuddihy et al., 2005; Morgan et al., 2003; Pangrazi et al., 2003; President's Council on Physical Fitness and Sports, 2002). They also suggest ways that pedometers might help teachers assess their teaching to demonstrate highly active lessons (Beighle et al., 2001).

In short, manufacturers and educators argue that pedometers can effectively supplement more traditional forms of instruction. However, as researchers analyzing curricular innovations suggest (e.g., McCaughtry \& Rovegno, 2003; McCaughtry, Sofo, Rovegno, \& Curtner-Smith, 2004; McCaughtry \& Wojewuczki, 2003; Rovegno, 1992), the logical leap from innovation and advocacy to widespread and effective implementation is mediated by teacher learning and development, as well as by the practical and contextual realities of hectic and busy classrooms.

Most researchers examining curricular innovations in such areas as constructivist-movement education (Logsdon, Alleman, Clark, \& Sakola, 1986), sport education (Siedentop, 1994), and adventure education (Panicucci \& Constable, 2001) have used cognitive developmental theories (Farnham-Diggory, 1992; McCaughtry et al., 2004; McCaughtry \& Wojewuczki, 2003; Rovegno, 1992; Shuell, 1986) to understand how teachers learn to integrate new curricula into their teaching.

Generally speaking, these researchers have found that teachers find some concepts easy to understand and implement in practice and others confusing and difficult. They have also found that teachers' implementation of innovation partially depends on their in success merging innovation with their past thinking and teaching. For example, Rovegno $(1992,1993,1998)$ found that teachers learning a constructivist curriculum overgeneralize the similarities between new and previous models; oversimplify new approaches; rely on bottom-up thinking; and are 
influenced by the reactions and support of students, mentors, administrators, and parents. Similarly, McCaughtry et al. (2004) found that teachers learning the sport education (Siedentop, 1994) model were apt to struggle with tactical (versus skill) instruction, and misunderstand the different approach to skill development. Moreover, in the adventure education setting, McCaughtry and Wojewuczki (2003) found that new teachers struggle at differentiating social themes embedded in activities, at moving beyond surface-level debriefings, and at getting past the uncomfortableness of teaching the social side of physical education.

Both McCaughtry et al. (2004) and McCaughtry and Wojewuczki (2003) illustrated the combined influences of cognition and values from a developmental learning perspective. The above studies showed the importance of cognitively understanding curricular models and how they function in real classrooms to the learning of new teaching practices. However, as Farnham-Diggory (1992) suggested, learning is not simply about cognitively understanding new content; rather, it is just as much about how learners feel about the content to be learned and how they feel about it after they have learned and experienced it in context. For example, McCaughtry et al. (2004) showed that preservice teachers initially valued the possibilities they saw in teaching the sport education model when they learned it in the university classroom. However, once they had an opportunity to teach the model in real classrooms, their perspectives (values) about the effectiveness of the model soured markedly. This showed that along with shifts in their cognitive understanding of how the model worked, their values for it were inextricably linked. Therefore, any study of learning from a developmental perspective must account for the cognitive elements of understanding new practices and teachers' changing values for it.

Although the research using developmental learning theory has focused primarily on preservice teacher learning, it should also have utility in helping us better understand how in-service teachers learn through workshop-based professional development (by far the most popular and widespread method of professional development). As Cothran, McCaughtry, Hodges Kulinna, and Martin (in press) showed, sometimes when teachers attend professional development workshops they grow excited about educational innovations and are eager to integrate them into their classrooms. However, when they return to their schools, they report feeling confused and frustrated as they forget what they learned or have difficulty integrating what they learned into their specific classrooms. Using developmental learning theory to understand the shifts in teachers' thinking and feelings as they transition from the workshop setting back to their classrooms may help those leading professional development to better design their efforts for teachers and help them prepare for the pitfalls or challenges the teachers may encounter. Of course, teachers attend professional development workshops for various reasons, and often are not excited or motivated to learn and change what they do. However, for teachers who do value what they learn at workshops and want to try new things, developmental learning theory might be quite useful in helping them transition from workshop learning to classroom implementation by knowing in advance what to look out for and how to think about the transition.

What all this means is that simply assuming that teachers will easily understand and develop positive values for new educational innovations and implement them successfully into their teaching may be ill conceived. Curricular innovation 
researchers illustrate the important need to specifically examine how teachers learn to teach and value new educational innovations. In doing so, they document concepts that teachers find confusing, pitfalls they encounter when implementing innovation, and strategies they discover on-the-fly to cope with trouble.

Therefore, the purpose of this study was to use cognitive developmental theory (Farnham-Diggory, 1992; Shuell, 1986) to identify important shifts in teachers' thoughts and feelings as they learned to use pedometers in their teaching. Following this theoretical framework, we studied three phases of the learning process. First, we analyzed teachers' initial thinking and feelings about pedometers and the role they could play in their classrooms. Second, we studied the challenges and successes the teachers reported as they integrated pedometers into their teaching. Third, we captured how the teachers understood and felt about pedometers after having had prolonged experiences with them. We specifically searched for shifts in teachers' thinking and feelings (values) regarding pedometers and learning. We wanted to know, from teachers' perspectives, what they believed were key moments in learning to use pedometers, whether they included confusing issues, moments of realization, successes in classrooms, or feelings of frustration. Similar to studies of preservice teacher learning, we were keen to understand the "qualitative shifts" (FarnhamDiggory, 1992) in in-service teachers' thinking and feelings about using pedometers throughout the workshop-to-classroom transition that could yield insights about the possibilities and limitations of pedometers in physical education.

\section{Methods}

We conducted this interpretivist, qualitative (LeCompte \& Preissle, 1993) research in a mid-sized border town in the Southwestern United States. The local school district educates approximately 10,000 elementary students, $70 \%$ of whom are Hispanic, 26\% are Caucasian, and 3\% are African American. Sixty-one percent are labeled "economically disadvantaged."

This study is part of a larger project pseudonymously called the Village Health and Physical Activity Initiative, whose aim is to increase youth health by improving elementary physical education. Several years before the project, many schools throughout the district adopted the Coordinated Approach to Child Health (CATCH) program. Teachers in diverse subjects learned to integrate the program in their various disciplines, and numerous physical educators were included. The current project was designed to continue the implementation of CATCH across the entire district by helping the physical education teachers who were already teaching $\mathrm{CATCH}$ to develop further, and provide initial training to any physical education teachers who had joined the district without $\mathrm{CATCH}$ experience. All 26 elementary physical education teachers (12 males, 14 females; 16 White, 7 Hispanic American, 2 Mexican American, 1 Asian American; 7.9 average years of teaching experience; 39, average age) from all 24 elementary schools volunteered to take part. We obtained informed consent from the internal review board at the local university, school district, teachers, and students.

The project spans 3 years. In the first year, teachers learned to teach the CATCH curriculum (Perry et al., 1990). They attended five full-school-day workshops across the year and received curriculum resources and physical education equipment 
packages. At the workshops, teachers learned new aspects of the curriculum, practiced teaching lessons to one another, and returned to their schools to practice it in their classes. At subsequent workshops, they discussed their experiences, offered one another feedback, and learned new aspects of the curriculum.

The current study was conducted during the second year of the project and focused on integrating two instructional technologies-pedometers and personal digital assistants (PDAs) — to assist the teachers' CATCH instruction. Earlier, teachers had voiced support for the idea that pedometers could help them achieve their CATCH mission of teaching physical activity and fitness content, and teaching all content in highly active ways. First, the teachers attended a pedometer workshop in August and learned about many aspects of pedometers, including how to use them, how to use them with children, and how to integrate them into instructional lessons. They were also given 30 dual-function pedometers from a reputable manufacturer that measured steps and activity time, along with curriculum materials and an instructional text (Pangrazi et al., 2003). They listened to a presentation from the workshop leader, engaged in discussion sessions, and were peer-taught PE lessons using pedometers. From early August until October, the teachers practiced using pedometers in their teaching. Next, in October, the teachers attended a second pedometer workshop, at which they shared their experiences with one another, offered feedback, learned more about teaching with pedometers, and peer-taught mini-lessons. After this workshop, the teachers again returned to their schools to practice using pedometers until the end of the semester (December).

\section{Data Collection}

We conducted this study during the 6 months the teachers learned to use pedometers. We used three main forms of data collection. First, we recorded field notes during both pedometer workshops, being careful to capture the content of the instruction given by the presenter and the dialogue between teachers, presenters, and other staff members (Patton, 2002). These field notes allowed us to understand what teachers knew about pedometers initially, and how they felt about including them in their teaching. Second, the informal conversations that took place between the researchers and the teachers during both workshops were recorded through field notes (Patton, 2002). The researchers often informally asked teachers what they thought about the pedometers, what was confusing, and whether they saw value in using them. After these conversations, the researchers recorded the content of the talk and the specific word-for-word dialogue they could remember. Last, and most importantly, we interviewed each teacher twice during his or her implementation of the pedometers at school. We first interviewed them during late September and early October, after they attended the first workshop and begin teaching with pedometers. We conducted interviews individually at the teacher's home school. Interviews lasted between 45 and $60 \mathrm{~min}$, were semistructured (Flick, 2006), and followed an interview guide with extensive probing and conversational discussion. In the first interview, we focused on the teachers' perceptions of the first workshop, the pedometers, and their experiences in using them to teach. The interview guide focused on issues that surfaced during the first workshop (e.g., content presented, teachers' informal questions and discussions), and provided us with wide-ranging probes to enable teachers to express any and all perceptions about pedometers and 
teaching. All interviews were audio-recorded and later transcribed. We interviewed each teacher a second time in January and February. In these interviews, we elicited the teachers' perceptions of the second pedometer workshop and their overall experiences teaching with them. We asked teachers to express their perspectives, as well as to informally member-check what we had learned from the first round of interviews and analysis.

\section{Data Analysis}

We analyzed the data using constant comparison (Glaser, 1969) throughout the project. First, we recorded all field notes and informal interviews from the first workshop electronically. Reviewing this data, we identified important issues for the presenter and teachers regarding workshop design, pedometer potential, philosophical issues about using pedometers, and learning to implement them into PE. These key issues framed the first interview, during which we asked teachers about every aspect of the workshop, the pedometers, and their teaching based on what we had gleaned from reviewing the fieldwork data. During the interviews, we probed the teachers' perspectives extensively and looked for other issues that we had not predicted. After the first interviews, we conducted constant comparison by coding each discrete excerpt of data. We combined data with similar codes to form wider explanations of these teachers' perspectives on pedometers. We paid particular attention to identifying changes or shifts in the teachers' understanding and feelings/values regarding pedometers from the beginning workshop until the first interview. We took these first interview interpretations and combined them with the events during the second pedometer workshop and created the second interview guide. During the second interview, we sought to elicit new or evolving perceptions from the teachers, as well as to ask them to clarify, refine, or refute what we interpreted from the first interviews. After reading the second interview transcripts several times, we again coded the data and searched for data that could create new explanations of the teachers' perceptions of learning to use pedometers in physical education. We also used the teachers' responses to our member-checking questions to refine or dismiss our initial interpretations that we had developed through data analysis after the first interview. This process of observing workshops, informally talking with teachers; formally interviewing them; and then again observing, talking, and interviewing over 5 months enabled us to identify four distinct interpretations that explained important shifts in the teachers' thinking and feelings about pedometers.

We did a number of things along the way to facilitate trustworthiness in the research (Lincoln \& Guba, 1985; Patton, 2002). First, the informal member checking that we did during the second interview proved invaluable in clarifying and achieving accuracy in our findings. In most cases, the teachers remarked that we had in fact identified key issues for them and they then offered tremendous detail to help us refine our interpretations. Second, we kept an extensive researcher journal tracking our interpretations as they evolved. Third, the second and third authors served as peer debriefers for the first author, who conducted a majority of the analyses for the study. They challenged him to offer clear and concise interpretations laced with specific data to support those interpretations. The peer debriefers were also integrally involved in all aspects of the project. They knew the teachers, attended 
the workshops, and knew the project from an insider's perspective, which increase their ability to provide direction and input to the first author.

\section{Results}

The teachers in this study experienced four substantive shifts in their thinking and feelings about using pedometers to supplement their instruction. At the beginning workshop, when they first learned how to use them in their classes, they were very excited and motivated. The mood was decidedly pro-pedometer. As a rule of thumb, based on the content of the teachers' discussions with the presenter, with one another, and with the research team, the teachers were quick to point out the upsides of pedometers and quick to gloss over the challenges of using them. There was a genuine energy about the way the teachers talked about pedometers and what they might do for their teaching. They foresaw few difficulties in using them, knew exactly who would enjoy and benefit from them most, identified ways of using them to teach almost any content, and foresaw them as potential mechanisms to illustrate their quality as teachers through student and self-evaluations. However, after using them in their teaching over several months, they grew increasingly pessimistic about whether pedometers were practical in physical education classes. On the one hand, they still voiced some positive ways that pedometers could, and sometime did, improve their abilities to engage students in physical activities, teach content, and monitor their teaching. On the other hand, they also reported numerous concerns about and limitations of using pedometers in their education settings. Their shifts in perspectives tell a cautionary tale about whether and how this form of technology might be useful in physical education and provide important insights into how in-service teachers' knowledge and values for pedometers shift as they move from the ideal world of professional development workshops to the realities of classrooms.

\section{Shifts Toward Concerns About Implementation}

From the initial workshop until the end of the study, the teachers' feelings about implementing pedometers into physical education shifted dramatically. As stated earlier, at the initial workshop, each of the project personnel commented on the excitement and motivation the teachers expressed regarding how they could use pedometers. Although the workshop presenter foreshadowed implementation challenges they might encounter, the teachers generally saw themselves as strong classroom managers, who could overcome "minor setbacks" or "obstacles" that could arise. The general feeling seemed to be that, yes, they would likely have some trouble with the pedometers but that their skillfulness in teaching would enable them to easily troubleshoot any potential obstacles. What they grew to realize by the end of the project was that a litany of implementation issues posed serious limitations to their abilities to use pedometers.

Getting Pedometers to Read Accurately. The time it took to help students mount the pedometers properly, so that they captured accurate step counts, represented one of the most frustrating and concerning aspects of learning to teach with pedometers. First, teachers reported difficulty in helping students mount them on 
their clothing properly. Tina said, "Getting those darn things positioned correctly on each kid every day is my biggest headache." It was particularly difficult when, for example, boys wore baggy pants. Ben lamented, "lots of my boys wear their pants so low, there's no way they put this thing on right." Other complicated issues arose when girls wore sundresses or other students wore pants with loose elastic waistbands. Students would understand how to mount the pedometers properly one day, but would have trouble the next when they wore different clothing. Matching pedometers to students' day-to-day clothing proved a lot more troublesome than most of the teachers expected.

Even when students wore the proper clothing, teachers reported that at least two to four pedometers would not read steps accurately. Most teachers had students mount the pedometers and then do some sort of walking test. Frustration resulted when for no apparent reason two to four pedometers were not working. This situation posed a dilemma. Do they waste more class time addressing those students' difficulties or do they temporarily dismiss them and move into content? This dilemma often soured teachers on using pedometers: "They're hard to use when they take at least 10 to 15 minutes of my 30-minute lesson to get them working. Whatever extra I can teach the kids with them is lost when I'm not teaching them at all" (Jordan). Overall, they felt that getting pedometers mounted and working correctly took valuable teaching time and student practice. Second, they also felt these hassles negatively affected their emotional relationships with students. The teachers were "on edge" trying to solve this dilemma quickly, which sent a certain "frustrated" message to students. John said, "It's frustrating because the kids bring it to my attention and want it solved; that's when I get frustrated about it." As a result, students grew increasingly frustrated, which framed their overall orientation to the lesson. Miguel said that the pedometer is "not effective and it's frustrating for the kids. . . . Accuracy is a big deal for the kids." Luis said, "They get really frustrated when they don't work; you can see a big change in their personality." In the final interview, nearly every teacher said that pedometer mounting and accuracy was a greater problem than they had anticipated.

One Class at a Time. At the initial workshop, the teachers foresaw little difficulty in using the pedometers with all of their upper elementary classes at one time. The common response was, "kids come in, take one, use it, drop it off on the way out, and you're done." However, by the end, many teachers advocated using their pedometers with one class at a time. They claimed the process of maintaining pedometers, tracking them, and making sure they worked properly was far too extensive for them to use with every class. Bridget said,

After the workshop, I was really gung-ho and tried to use them in all my upper [elementary] classes, but that was hard. My head was spinning. I couldn't keep track of who had what, which ones weren't working, yada, yada, yada.

A better approach they found was to rotate using them with their different classes on a weekly basis. This strategy kept students from getting bored, while also preserving the teachers' sanity.

Students' Constant Monitoring. At the beginning, the teachers did not fully understand how much interruption would be caused by students' often checking 
their step counts. Most teachers thought it would be positive because it would further motivate students. By the end, most teachers believed that a good deal of class time was wasted when students constantly checked their step counts or activity time and compared them. Sandra said, "Here I am teaching these kids something and half of them are farting around with their pedometers and showing each other. I want them active and they just want to fool with those things." To combat this, they developed periodic group checks, where they stopped class, checked step counts, shared them, and got back to activity. This provided a more efficient way of making sure all students had an opportunity to know their step counts, have them acknowledged, and get back to learning.

Shaking the Pedometers. Although the teachers initially thought that some students would attempt to build their step counts by shaking their pedometers, they did not fully understand how widespread the problem would become. Indeed, they found that students often wanted to shake their pedometers rapidly to increase their step counts. Maria said, "They all want to have the highest step counts or see how much they improved and most of them quickly realized that if they shake the pedometer or tap it on their leg they can boost their scores. . . I It became a big distraction." Many teachers quickly realized that they needed to talk with students collectively about honestly using the pedometers and devised behavior management for students who continued shaking them. Most agreed that they should have been more proactive and have talked with the students about shaking before they handed them out and had clearly stated consequences. Mona said, "I could have gotten in front of this by taking the bull by the horns from the start. I should have set clearer boundaries and not just given them to them."

Pedometer Durability and Maintenance. C Contrary to their feelings at the beginning, by the end of the year, many teachers felt that, although pedometers might play a role in enhancing their teaching, they were not durable enough for consistent, rugged, and long-term use in physical education. Their pedometers were touted by the manufacturer as dependable and trustworthy. However, each and every teacher experienced numerous difficulties with durability. Of course, the manufacturer offered free replacements for broken pedometers, the workshop presenter showed them how to replace dead batteries, and explained how inexpensive and easy they were to purchase. But, the devices' durability frustrated many teachers and students. Javier explained,

I don't know how long I'll be able to use these. Everyday I'm having to figure out why they aren't working. I have a whole pile that don't work and now I have to try to figure out how to send them back. For what I get out of them, I sometimes don't think it's worth the hassle.

\section{Shifts in Student Reactions}

At the outset, the teachers suggested in numerous discussions at the first workshop that pedometers would motivate students, especially the higher skilled and more competitive ones who would want to track their step counts and compete with one another. However, quite surprisingly, they found that lower skilled students were 
in fact the ones who developed stronger connections with the pedometers. All students were motivated at first and increased their engagement in lessons because the pedometers were new and provided immediate feedback, and students could compare scores among one another. However, after the immediate novelty wore off, the lesser skilled and less active students appeared to remain excited about the pedometers longer. They asked to use the pedometers more often, wanted to converse with the teachers about them more, and engaged more in the cross-disciplinary or outside-the-school activities. The more skilled students, especially boys, seemed to lose interest sooner and wanted to begin activities more quickly. They viewed the pedometers as deterrents to their physical activity. Maria explained, "The higher skilled kids just want to go, go, go. For them, spending time putting those on and getting them to work right just takes time they could be playing."

Although the teachers wanted to avoid alienating the higher skilled students by continuing to use the pedometers, they also enjoyed the fact that pedometers enabled them to connect with their lesser skilled or more sedentary students. Luis said, "I've found that that the inactive kids really like these, maybe they want to avoid being labeled inactive, or maybe they just see some sort of challenge in themselves." Linda had a similar perspective:

You know, I think those kids out there that can run and jump just fine, but can't throw a football or shoot a basketball, really buy into these things. Maybe it levels the playing field or gives them something they are good at and can show it. . . Whatever, they really seem to like using these.

For some teachers, these reactions seemed odd and not at all what they had predicted. Most predicted that their higher skilled students would like them most because they were the ones who could score the best. Many were surprised, yet delighted, that the lower skilled and less skilled students seemed to embrace pedometers more and want them as part of their learning.

\section{Shifts in the Possibilities for Content Instruction}

At the first workshop, the teachers engaged in extensive discussions about the content that the pedometers might enhance their ability to teach. In those discussions, they suggested that pedometers in one way or another could enhance their instruction in many areas of content such as motor skills, fitness concepts, and sport skills. In fact, after a long and protracted brainstorming session, one teacher commented that, "the sky's the limit." That perspective changed dramatically by the end of the semester, as they narrowed and refined the list of content they could use pedometers to teach into four main objectives: teaching students their real activity levels, teaching them the differences in physical activity intensities, exploring cross-curricular connections between movement and classroom subjects, and modeling active lifestyles. First, the teachers believed that there often exists a disparity between students' perceived and real activity levels. It was important to have students understand whether they were obtaining the quantity of physical activity that they thought they were, because some students believe they are far more active than they really are. Sam claimed, 
Lots of these kids are like wallflowers. They are out there on the playground or the field, but they're basically just standing there, and not really moving or playing. These pedometers can help them see that they actually aren't playing as much as they think. They need to know that so they don't think that just being there is physical activity.

Second, they felt it was important to teach students the intensity levels of various physical activities. They wanted students to know how many steps $15 \mathrm{~min}$ of tag accrued versus walking, speed walking, jogging, basketball, football, and soccer. William said,

Kids need to be able to recognize that jogging has more health benefits than walking-you simply go further in the same amount of time. Sometimes I think kids think that everything has the same amount of activity or that walking is just as "cardio" as basketball. They just aren't the same, so I wanted kids to feel the differences and see the scores between these activities.

Third, at the beginning, the teachers were excited about the possibilities of teaming with classroom teachers and creating cross-curricular units. For example, during workshops, lots of the teachers immediately latched onto a Internet program where students logged their steps and tracked their progress toward different locations across the United States. They also liked the mathematics involved in figuring stride length and calculating distances with steps. Most expressed a willingness to collaborate with classroom teachers, but, unfortunately, many who approached classroom colleagues encountered resistance because they perceived physical education as just "playing games" and had little to offer real classroom subjects. Or, if classroom teachers were interested, they wanted the PE teacher to teach some cross-curricular content, which they would reinforce in the classroom. Very few of the classroom teachers were genuinely interested in co-constructing meaningful and substantive cross-curricular units. This disinterest decreased the motivation of the PE teachers, even though they recognized cross-curricular possibilities. This was not always the case. A few of the teachers reported very receptive classroom teachers, but this was by far the exception rather than the norm.

Last, many teachers thought that wearing pedometers themselves modeled physically active lifestyles for their students. Maria explained,

I wore one throughout the day and the kids would say, "why are you wearing that?" So I would explain it to them and they kind of got the idea that this becomes part of your lifestyle. Somewhere the fifth graders were asked, "do you feel your coaches and teachers encourage physical activity and are they?" Well, I see that us using the pedometers ourselves to the kids shows that physical activity is important.

A few teachers used the pedometers to create after-school exercise clubs with students and other faculty members. In these ways, the teachers used pedometers not necessarily to teach content as much as to teach students about making physical activity a part of their regular lifestyle. Over this 6-month trial, the teachers started to view pedometers as less the magical devices to help them teach a wide range of content and instead became more realistic about the limits of pedometer use. 


\section{Shifts About the Possibilities for Teacher Improvement}

At the first workshop, the presenter discussed ways in which teachers might use pedometers to track student learning and evaluate their own teaching. The teachers almost immediately latched onto this notion of accountability. Many described feeling very marginalized and disrespected as physical education teachers. Thus, some suggested that by using pedometers to document-objectively and numerically - the kinds of learning and teaching that occurred in physical education, they could boost their visibility and profiles in their schools.

By the end of the semester, however, the teachers argued that although pedometers could theoretically help them in these ways, practically, it was impossible. In particular, they seemed to feel that the difficulty at getting pedometers to work properly in some situations could end up doing more harm than good. They were hesitant, for example, to use any pedometer results to make assumptions about their teaching, beyond loose guides. Pedro said,

These things aren't accurate enough for me to say anything with certainty about my teaching. Like, I'll have this really active lesson, but when I go to check their pedometers, they're all over the board. If one kid's [pedometer] says 18 minutes [of activity time] and another says 6, how does that help?

They were, however, a little more open to using the pedometers to hold students accountable for their activity during lessons. Enrique claimed, "Yeah, I can look at a kid's pedometer after class and tell them, 'you know, you need to be more active.' That way they know that I'm watching them." But, some of the teachers felt as though this accountability had to be used very cautiously because if pedometers were not yielding accurate results, then students could be reprimanded or given false praise based on inaccurate data. In the end, they grew increasingly vocal in their opposition to using pedometers as accountability tools for their teaching or for their students' learning.

\section{Discussion}

In this study, cognitive developmental learning theory proved quite useful in understanding how in-service elementary teachers' thinking and values regarding pedometers changed as they learned about them in workshops and tried them in their classes. Their early assumptions about the ease of use, motivation for high-skilled students, use for all realms of content, and opportunities for accountability proved faulty when they learned about implementation problems, that lesser skilled students enjoyed them more, that they were applicable to teaching a more refined and finite range of content, and that use for accountability may be unrealistic. Pedometers have become a widespread educational innovation for physical education teachers, but until now a research base examining how teachers incorporate them into their work has been lacking. The shifts in these teachers' thinking should serve as a pause for concern about whether this widespread promulgation of pedometers is finding success, especially for in-service teachers.

From a cognitive developmental perspective, this study varies slightly from teacher learning studies in other areas. In research examining how teachers learn 
new curricular models, most researchers have identified difficulties teachers have in understanding the nuances of new approaches compared with their previous teaching. In adventure education, teachers struggle to understand the social side of content and differentiate among social themes (McCaughtry \& Wojewuczki, 2003). In sport education, teachers find it confusing to teach a tactical skill model as opposed to decontextualized drills (McCaughtry et al., 2004). Also, teachers learning a constructivist curriculum fail to fully appreciate how different these approaches are and tend to overgeneralize similarities across models (Rovegno, 1992, 1993).

In contrast to these studies, our elementary teachers' shifts in thinking centered on realizations about practicality and the disparities between the possibilities of pedometers that they foresaw in their early exposures to them at workshops and the realities of using them in their classrooms. As Doyle and Ponder (1977) many years ago and recently Cothran et al. (in press) have noted, issues of practicality dominate teachers' thinking and their acceptance, rejection, or reformulation of innovation. Cothran et al. (in press), for example, found that teachers' learning focused primarily on whether innovation met their immediate and contextual needs; whether it provided sufficient, but not too much, explanation and detail; and whether it fit with the equipment and cultural resources of their schools. In this case, our teachers' most pronounced shifts in thinking concerned the practicality-based travails of using the pedometers in their classes. In the end, the teachers seemed to think that the current state of pedometry was not advanced enough for the hectic, time-sensitive, and rugged nature of physical education. They were concerned that pedometers were too difficult to mount on students, they were often inaccurate, and they were too easy for students to abuse. Between the time constraints of 30-min lessons and nearly constant maintenance and attention, they often viewed the tradeoff between the possible educational outcomes and the practicality of pedometers as one they might not be willing to make.

This same ethic of practicality also seemed to dominate their thinking about using pedometers to assess their teaching. Whereas advocates suggest that pedometers can help teachers demonstrate their physical activity outcomes (Beighle et al., 2001), these teachers discovered that the time needed to get students' pedometers mounted and working correctly, combined with inconsistent accuracy, limited the extent to which pedometers were viable accountability tools. The possibility of quantifying students' activity did not negate the fact that they lost much valuable instructional time simply struggling with the logistics of getting them to work. In addition, they were quite reticent to use pedometer data gleaned from the nonstandardized applications in their classrooms to make any claims about their teaching effectiveness.

The teachers also voiced an increased ability to teach educational content that is fairly consistent with pedometer literature (Beighle et al., 2001; Cuddihy et al., 2005; Morgan et al., 2003; Pangrazi et al., 2003; President's Council on Physical Fitness and Sports, 2002). They found they could teach students how active they really are and the differences between the intensities of various activities. They could also motivate students, although a new finding was how well they could motivate lesser skilled students and how soon higher skilled students were to view them as activity constraints. They also discussed multidisciplinary or cross-curricular connections between the pedometers and academic subjects consistent with 
a growing movement in this area (Buchanan et al., 2002; Hatch \& Smith, 2004; Placek \& O'Sullivan, 1997). However, as these teachers caution, a multidisciplinary curriculum may be fine in theory, but it requires acceptance on the part of coresubject classroom teachers, who often show little respect for physical educators (McCaughtry, Martin, Hodges Kulinna \& Martin, 2006a). This study shows that pedometer literature reinforcing cross-curriculum use might also include strategies for working with resistant classroom teachers.

Last, the study shows how interconnected learning new innovation is with the relationships between students and teachers. Maintaining a positive emotional connection with students is paramount in teachers' work (Hargreaves, 1998) and influences most of their thinking about teaching (McCaughtry, 2004, 2005). It also shapes and shades how they learn new educational innovations (McCaughtry et al., 2006a; McCaughtry, Martin, Hodges Kulinna \& Cothran, 2006b). In this study, using pedometers was both a relational boom and bust. The pedometers improved the teachers' relationships with their students through the motivation from novelty, especially with lesser skilled students, with whom they typically had the most difficulty connecting. Conversely, the pedometers also at times negatively affected the teachers' interactions with their students. The combination of students' body sizes and attire, the inconsistent functioning of the pedometers, and the pressure to get classes started quickly to maximize learning time, resulted in very rushed, hasty, and often frustrating interactions between students and teachers. The teachers wanted to get into lessons, but every student wanted their pedometer working correctly. The perpetual dilemma of what to do in this very moment all-too-often soured the relationship between teachers and students.

There are many practical insights stemming from this study. Teachers must purchase or be given mechanically sound pedometers. Their suggestions for improving pedometers included: better belt mounting clips, longer lasting batteries, more shock resistance, pedometers mounted on drawstring belts, diagrams for mounting them on wall posters or the pedometers, and ones that resist shaking or tapping to elevate step counts. These recommendations challenge manufacturers to construct more durable products for physical education, and for school districts to purchase better quality pedometers meeting these specifications.

More generally, these results provide guidance to those educating in-service teachers in using pedometers. Many teachers, but certainly not all, come to professional development workshops and are attracted to what they learn; they get excited about using what they learned in their classrooms. But, too often we do not understand the challenges that teachers face when they make the transition from the workshop to implementing what they learned in their classrooms. For leaders of workshops on pedometers, this study provides clear guidance about how elementary teachers' perspectives on pedometers change once they leave the workshop and try them in real classrooms. From this study, teachers can be prepared for the challenges of mounting pedometers, and the need for behavior management plans for students who check and shake them. Teachers might also be prepared for higher skilled students to grow bored of the pedometers, but be open to lower skilled students engaging with them longer. Teachers should be warned about potentially unreceptive classroom colleagues and be given resources and strategies for working politically with those colleagues. Last, teachers should know what others like in them or find difficult and easy, and what others see as realistic possibilities. 
Future researchers should continue building a richer knowledge base as to how teachers learn to use pedometers. They should also seek to understand how students feel about them in the gym. Based on these teachers' anecdotal comments, different subsets of students may feel different about using pedometers. Qualitative studies documenting what students learn, how they respond, and how pedometers influence their activity time in real-world classrooms could prove valuable in determining the ultimate worth of pedometers in schools.

\section{References}

Beighle, A., Pangrazi, R.P., \& Vincent, S.D. (2001). Pedometers, physical activity, and accountability. Journal of Physical Education, Recreation and Dance, 72(9), 16-19, 36.

Buchanan, A.M., Howard, C., Martin, E., Williams, L., Childress, R., Bedsole, B., et al. (2002). Integrating elementary physical education and science: A cooperative problem-solving approach. Journal of Physical Education, Recreation and Dance, 73(2), 31-36.

Cardon, G., \& De Bourdeaudhuij, I. (2004). A pilot study comparing pedometer counts with reported physical activity in elementary schoolchildren. Pediatric Exercise Science, 16, 355-367.

Cothran, D., McCaughtry, N., Hodges Kulinna, P., \& Martin, J. (in press). Physical education teachers and mandated public health curricular change. Journal of In-Service Education.

Crouter, S.E., Schneider, P.L., Karabulut, M., \& Bassett, D.R. (2003). Validity of 10 electronic pedometers for measuring steps, distance, and energy cost. Medicine \& Science in Sports and Exercise, 35, 1455-1460.

Cuddihy, T.F., Pangrazi, R.P., \& Tomson, L.M. (2005). Pedometers: Answers to FAQ's from teachers. Journal of Physical Education, Recreation and Dance, 76(2), 36-40, 55.

Doyle, W., \& Ponder, G. (1977). The ethic of practicality. In A. Molnar \& J. Zahorik (Eds.), Curriculum Theory (pp. 74-80). Washington, DC: Association for Supervision and Curriculum Development.

Farnham-Diggory, S. (1992). Paradigms of knowledge and instruction. Journal of Educational Psychology, 84, 463-477.

Flick, U. (2006). An introduction to qualitative research. Thousand Oaks, CA: Sage.

Glaser, B.G. (1969). The constant comparative method of qualitative analysis. In G.J. McCall \& J.L. Simmons (Eds), Issues in participant observation (pp. 245-289). Reading, MA: Addison-Wesley.

Hargreaves, A. (1998). The emotional practice of teaching, Teaching and Teacher Education, $14,835-854$.

Hatch, G.M., \& Smith, D.R. (2004). Integrating physical education, math, and physics. Journal of Physical Education, Recreation and Dance, 75 (1), 42-50.

Kilanowski, C.K., Consalvi, A.R., \& Epstein, L.H. (1999). Validation of an electronic pedometer for measurement of physical activity in children. Pediatric Exercise Science, 11, 63-68.

LeCompte, M.D. and Preissle, J. (1993). Ethnography and qualitative design in educational research (San Diego, Academic Press).

Lincoln, Y.S. \& Guba, E.G. (1985). Naturalistic inquiry. London: Sage.

Logsdon, B.J., Alleman, L.M., Clark, D., \& Sakola, S.P. (1986). Physical education teaching units for program development grades $K$-3. Philadelphia: Lea \& Febiger.

Louie, L., \& Chan, L. (2003). The use of pedometry to evaluate the physical activity levels among preschool children in Hong Kong. Early Child Development and Care, 173, 97-107. 
McCaughtry, N. (2004). The emotional dimensions of a teacher's pedagogical content knowledge: Influences on content, curriculum, and pedagogy. Journal of Teaching in Physical Education, 23, 30-47.

McCaughtry, N. (2005). Elaborating pedagogical content knowledge: What it means to know students and think about teaching. Teachers and Teaching: Theory and Practice, $11,379-395$.

McCaughtry, N., Martin, J., Hodges Kulinna, P., \& Cothran, D. (2006a). Emotional dimensions of teacher change. Journal of Teaching in Physical Education, 25, 99-119.

McCaughtry, N., Martin, J., Hodges-Kulinna, P., \& Cothran, D. (2006b). What makes teacher professional development work?: The influences of instructional resources needed to change. Journal of In-Service Education, 32, 221-235.

McCaughtry, N., \& Rovegno, I. (2003). The development of pedagogical content knowledge: Moving from blaming students to predicting skillfulness, recognizing motor development, and understanding emotion. Journal of Teaching in Physical Education, 22, 355-368.

McCaughtry, N., Sofo, S., Rovegno, I., \& Curtner-Smith, M.D. (2004). Learning to teach Sport Education: Misunderstandings, pedagogical difficulties, and resistance. European Physical Education Review, 10, 135-156.

McCaughtry, N., \& Wojewuczki, J. (2003). Learning to teach socially critical adventure education in elementary physical education. Research Quarterly for Exercise and Sport, 74, A50.

Morgan Jr., C.F., Pangrazi, R.P., \& Beighle, A. (2003). Using pedometers to promote physical activity in physical education. Journal of Physical Education, Recreation and Dance, 74(7), 33-38.

Pangrazi, R.P., Beighle, A., \& Sidman, C.L. (2003). Pedometer power. Champaign, IL: Human Kinetics.

Panicucci, J., \& Constable, N.S. (2001). Adventure curriculum for physical education: Elementary school. Beverly, MA: Project Adventure, Inc.

Patton, M.Q. (2002). Qualitative research and evaluation methods. Thousand Oaks, CA: Sage.

Perry, C.L., Stone, E.J., Parcel, G.S., Ellison, R.C., Nader, P.R., Webber, L.S., et al. (1990). School-based cardiovascular health promotion: The child and adolescent trial for cardiovascular health (CATCH). Journal of School Health, 60, 406-413.

Placek, J.H., \& O'Sullivan, M. (1997). The many facets of integrated physical education. Journal of Physical Education, Recreation and Dance, 68(1), 20-24.

President's Council on Physical Fitness and Sports. (2002). Taking steps toward increased physical activity using pedometers to measure and motivate. Research Digest, 3(17), 1-8.

Rovegno, I. (1992). Learning to teach in a field-based methods course: The development of pedagogical content knowledge. Teaching and Teacher Education, 8, 69-82.

Rovegno, I. (1993). Content knowledge acquisition during undergraduate teacher education: Overcoming cultural templates and learning through practice. American Educational Research Journal, 30, 611-642.

Rovegno, I. (1998). The development of in-service teachers' knowledge of a constructivist approach to physical education: Teaching beyond activities. Research Quarterly for Exercise and Sport, 69, 147-162.

Rowe, D.A., Mahar, M.T., Raedeke, T.D., \& Lore, J. (2004). Measuring physical activity in children with pedometers: Reliability, reactivity, and replacement of missing data. Pediatric Exercise Science, 16, 343-354.

Schneider, P.L., Crouter, S.E., Lukajic, O., \& Bassett Jr., D.R. (2003). Accuracy and reliability of 10 pedometers for measuring steps over a 400-m walk. Medicine \& Science in Sports and Exercise, 35, 1779-1784. 
Scruggs, P.W., Beveridge, S.K., Eisenman, P.A., Watson, D.L. Shultz, B.B., \& Ransdell, L.B. (2003). Quantifying physical activity via pedometry in elementary physical education. Medicine and Science in Sports and Exercise, 35, 1065-1071.

Scruggs, P.W., Beveridge, S.K., Watson, D.L., \& Clocksin, B.D. (2005). Quantifying physical activity in first through fourth grade physical education via pedometry. Research Quarterly for Exercise and Sport, 76, 166-175.

Shuell, T.J. (1986). Cognitive conceptions of learning. Review of Educational Research, 56, 411-436.

Siedentop, D. (1994). Sport Education: Quality PE through positive sport experiences. Champaign, IL: Human Kinetics.

Tudor-Locke, C.E., \& Myers, A.M. (2001). Methodological considerations for researchers and practitioners using pedometers to measure physical (ambulatory) activity. Research Quarterly for Exercise and Sport, 72, 1-12.

Tudor-Locke, C.E., Williams, J.E., Reis, J.P., \& Pluto, D. (2002). Utility of pedometers for assessing physical activity: Convergent validity. Sports Medicine, 32, 795-808. 